\title{
MITIGASI DAN PENANGGULANGAN BENCANA BANJIR DEBRIS PASCA GEMPA PALU 2018
}

\section{MITIGATION AND COUNTER MEASURES OF DEBRIS FLOW DISASTER POST PALU EARTHQUAKE 2018}

\author{
C. Bambang Sukatja 1), Banata W.R 1), Perdi Bahri 1) \\ 1)Balai Teknik Sabo, Direktorat Bina Teknik Sumber Daya Air, Direktorat Jenderal Sumber Daya Air, \\ Kementerian Pekerjaan Umum dan Perumahan Rakyat, \\ Sopalan, Maguwoharjo, Depok, Sleman, Yogyakarta, Indonesia \\ ${ }^{*}$ Correspondent e-mail: cosabam@yahoo.com
}

Diterima: 16 Oktober 2020; Direvisi: 13 Januari 2021; Disetujui: 11 Februari 2021

\begin{abstract}
The 7.4 SR earthquake which occurred in The Donggala Regency, Central Sulawesi on September $28^{\text {th }} 2018$ was a shallow earthquake due to the Palukoro fault activity. The impact of the quake's shaking created pressure on the rock and soil masses of 77 hilly locations in the Palu, Sigi, and Donggala, causing several landslides and the increasing the potential of more. One of the slopes of at risk of landslides which can trigger debris flow is found on the hills of Poi Village, Dolo Selatan District, Sigi Regency. The estimated volume of lose material which could fall in a landslide is 4.8 million m3. Rainfall in the area is predicted to trigger debris flow with the potential to bury settlements and block the flow of the Palu tributary located downstream. For this reason, it is necessary to conduct a study of the lose material deposits in the Poi River channel which can trigger debris flows during the rainy season. The problem-solving method in this study used is a rationalistic and descriptive qualitative approach. In predicting the distribution direction, propagation and hydrograph of the debris flow ths study applies the numerical modelling SIMLAR 2.1. This debris disaster risk management effort uses Sabo technology physically and non-physically.
\end{abstract}

Keywords: earthquakes, landslides, debris flow, debris disaster management, Sabo technology physically and nonphysically.

\begin{abstract}
ABSTRAK
Gempa bumi sebesar 7,4 Skala Richter (SR) pada kedalaman 11 km yang terjadi pada tanggal 28 September 2018 di Kabupaten Donggala, Sulawesi Tengah merupakan gempa bumi dangkal yang diakibatkan aktivitas sesar Palukoro. Dampak getaran gempa bumi tersebut mengakibatkan 77 lokasi lereng perbukitan diwilayah Palu, Sigi, dan Donggala mengalami tekanan pada massa batuan dan tanahnya. Sebagian lereng bukit teridentifikasi telah mengalami longsor dan sebagian lainnya berpotensi longsor. Lereng perbukitan yang longsor dapat memicu terjadinya aliran debris di lereng perbukitan Desa Poi Kecamatan Dolo Selatan Kabupaten Sigi. Estimasi volume tanah longsor sebesar 4,8 juta $\mathrm{m}^{3}$ berupa material lepas yang belum terkonsolidasi. Ketika terjadi hujan diperkirakan akan memicu terjadinya aliran debris yang berpotensi menimbun permukiman dan aliran Anak Sungai Palu yang berada di bagian hilir. Sebagai upaya mitigasi bencana perlu dilakukan kajian terhadap endapan material lepas yang berada di alur Sungai Poi. Metode yang digunakan adalah pendekatan studi rasionalistik dan deskriptif kualitatif. Dalam memperkirakan arah sebaran, rambatan dan hidrograf banjir debris yang akan terjadi menggunakan aplikasi pemodelan numerik SIMLAR 2.1. Upaya penanggulangan risiko bencana debris ini menggunakan teknologi sabo baik secara fisik maupun non-fisik.
\end{abstract}

Kata kunci : gempa bumi, longsor, debris, penanggulangan bencana debris, teknologi sabo secara fisik dan non-fisik. 


\section{PENDAHULUAN}

Badan Meteorologi Klimatologi dan Geofisika (2018) melaporkan terjadinya gempa dengan magnitude 7,7 SR mengguncang $26 \mathrm{~km}$ utara Donggala-Sulteng Jumat (28/9/2018) OT 17:02:44 WIB, kedalaman $10 \mathrm{~km}$ yang kemudian dimutakhirkan menjadi magnitude 7,4 SR dengan OT 17:02:45 WIB, kedalaman 11 km. (BMKG, 2018). Gempa yang berpusat di Kabupaten Donggala Sulawesi Tengah merupakan gempa bumi tektonik. Goncangan gempa tersebut melanda wilayah Kabupaten Donggala, Kota Palu, Kabupaten Parigi Moutong, Kabupaten Sigi, Kabupaten Poso, Kabupaten Tolitoli, Kabupaten Mamuju hingga Kota Samarinda, Kota Balikpapan, dan Kota Makassar. Gempa bumi tektonik dangkal tersebut merupakan jenis gempa yang labil, dengan kata lain, suatu saat gempa serupa akan berulang. (Suardiari. G. dkk., 2019). Lokasi gempa tersebut seperti terlihat pada Gambar 1.

Gempa yang terjadipada 28 September 2018 pukul 17:02:45, disertai gempa susulan sebanyak 209 kali dan berakhir pada 30 September 2018. Memperhatikan dari lokasi episenter dan kedalaman hiposenter, gempa dipicu oleh aktivitas sesar Palukoro Donggala. Hasil analisis mekanisme sumber gempa tersebut dibangkitkan oleh deformasi dengan mekanisme pergerakan dari struktur sesar mendatar.

Jalur sesar aktif Palukoro tersebar memanjang dari Teluk Palu ke Selatan hingga daerah Sigi. Panjang pergerakan sesar dari lokasi pusat gempa hingga lokasi terdampak diperkirakan sekitar 155 $\mathrm{km}$ dengan lebar zona sesar sekitar $40 \mathrm{Km}$.

Gempa yang menghancurkan wilayah pesisir Teluk Palu juga memicu terjadinya tsunami yang menyapu pantai Talise dan Kota Palu serta mengakibatkan gerakan tanah/longsor dan likuifaksi di beberapa lokasi. Korban jiwa akibat bencana gempa dan tsunami sebanyak 2.256 orang. (BNPB, 2018).

Dampak getaran gempa bumi di jalur sesar aktif Palukoro mengakibatkan 77 lokasi lereng perbukitan diwilayah Palu, Sigi, dan Donggala mengalami tekanan pada massa batuan dan tanahnya. Pada Gambar 2, terlihat beberapa titik gerakan tanah yang dipicu gempabumi tersebut sehingga beberapa lereng bukit mengalami longsor dan berpotensi longsor.

Karakteristik anak Sungai Palu yang terletak di bagian hilir permukiman terlihat sempit di bagian hulu dan melebar di hilir menyerupai kipas. Sehingga apabila mendapat suplai material debris dari bagian hulu sungai berpotensi membentuk bendung alam. Kondisi ini telah terjadi pada tanggal 8 Desember 2019 ketika hujan dengan intensitas 46,8 mm yang memicu terjadinya aliran debris berskala kecil.

Studi tentang aliran debris dan sedimen sudah banyak dikembangkan di Indonesia. Pusat Studi Gempa Nasional bekerjasama dengan Pusat Litbang Perumahan dan Pemukiman - Balitbang PUPR pada tahun 2018 telah melakukan simulasi terkait potensi aliran debris pasca gempa Palu dengan menggunakan perangkat lunak pemodelan numerik dinamik RAMMS (Rapid Mass Movement). Simulasi tersebut dapat memprediksi terjadinya aliran debris yang akan melanda sebagian besar Desa Poi dalam bentuk sebaran material kipas alluvial. Sebagai upaya penanggulangannya perlu dilakukan normalisasi aliran pada alur yang tertutup material longsoran. Untuk mencegah terjadinya korban aliran debris maka aktivitas masyarakat yang berada di hilir longsoran khususnya di musim hujan harus berhati-hati.

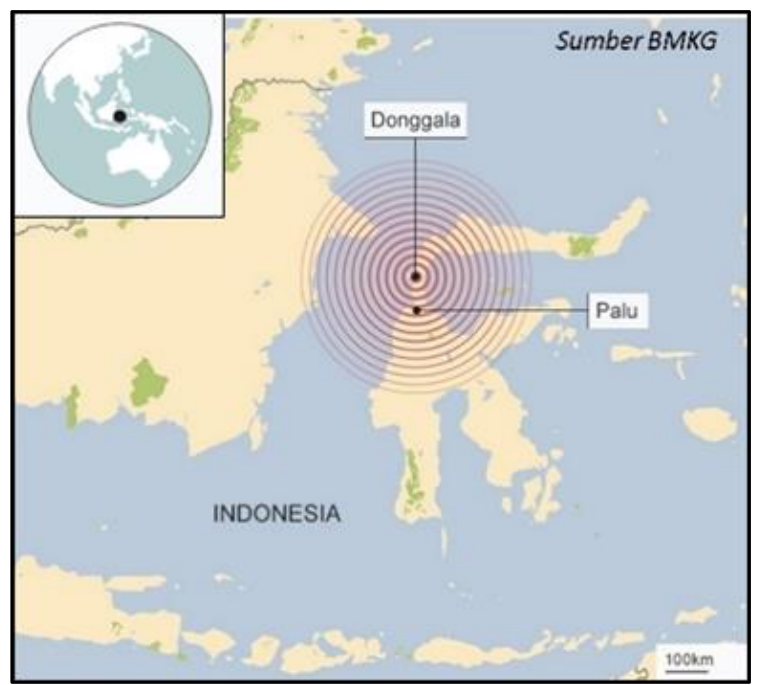

Gambar 1 Lokasi pusat gempa 7,4 SR, berpusat di daerah Sirenjadi, 11 kilometer timur laut Donggala 
Dalam memperkirakan terjadinya aliran debris perlu melibatkan warga dan aparat pemerintah setempat untuk mengetahui perkembangan material longsoran dan retakan yang terbentuk selama 24 jam. Sebagai upaya evakuasi, perlu dibuatkan lokasi pengungsian dan titik kumpul yang menjauh dari potensi aliran debris khususnya ke arah selatan (Menuju Desa Pulu).

Widjaja. B. dan Gautama. K. A. (2019) juga telah melakukan penelitian di Desa Poi Sulawesi terkait kajian debris, dengan menggunakan model Bingham melalui program FLO-2D. Hasil penelitian tersebut menyatakan bahwa area terdampak aliran debris sekitar 400 Ha dengan ketebalan maksimum 7,2 m dan kecepatan maksimum $11 \mathrm{~m} /$ detik. Rekomendasi yang disarankan dalam penanggulangan bencana aliran debris dengan cara fisik salah satunya menggunakan sabodam dan nonfisik seperti relokasi penduduk ke tempat yang lebih aman.

Hasil penelitian yang selama ini telah dilakukan berupa mitigasi bencana struktural dan non-struktural serta penanggulangan debris dengan cara fisik dan non-fisik yang diantaranya menggunakan sabodam dan relokasi penduduk. Sejauh ini belum ada penelitian yang memperhatikan faktor risko bencana debris dan mengembangkan pemikiran kearifan lokal agar penduduk tetap tinggal di daerah yang diperkirakan terdampak namun keselamatan mereka tetap terjamin.

Untuk itu, didalam penelitian ini dilakukan kegiatan pengkajian untuk mengisi 'research gap' yang masih ada. Diantaranya terkait dengan segala sesuatu yang akan terjadi dan solusi yang diperlukan di daerah pengkajian.

Diharapkan dari hasil kajian ini dapat diperoleh suatu upaya pengendalian aliran debris yang dapat meminimalisir kerugian material dan non material serta dapat mengajak masyarakat untuk biasa hidup berdampingan dengan bencana. (livingin harmony with disaster).

\section{METODOLOGI}

Dalam mengidentifikasi longsoran di lereng Desa Poi dan besaran potensi aliran debris yang diakibatkan oleh longsoran tersebut maka dilakukan kegiatan survei lapangan, pengumpulan data dan analisis data primer dan sekunder. Pelaksanaan survei lapangan dan pemetaan daerah longsor serta daerah yang diperkirakan terdampak debris dilakukan dengan menggunakan pesawat tanpa awak (Unmanned-aircraft Vehicle System) dari tanggal10 - 30 September 2019.
Untuk mengetahui perubahan morfologi sungai dan ancaman aliran debris berikutnya terhadap masyarakat disekitar dilakukan survei lapangan pada tanggal 9 hingga 13 Desember 2019 yang difokuskan untuk melakukan identifikasi daerah yang terdampak aliran debris dengan peralatan UAV.

Dari hasil pemetaan sebaran aliran debris yang terjadi pada tanggal 8 Desember 2019 dapat digunakan sebagai acuan dari hasil pemodelan SIMLAR meskipun nilai data hujan pemicunya masing-masing berbeda. Sedangkan untuk memperkirakan arah dan analisis hidrologi sebaran serta rambatan banjirnya dilakukan dengan pemodelan numerik aplikasi simulasi lahar/debris 2D, SIMLAR 2.1. Tampilan hasil simulasi menggunakan Sistem Informasi Geografi.

Untuk penanggulangan aliran debris jangka panjang di daerah pengkajian menggunakan teknologi sabo secara fisik maupun non-fisik. Dan untuk memahami berbagai permasalahan yang berhubungan dengan penggunaan teknologi sabo dalam penanggulangan aliran debris dilakukan dengan cara pendekatan yang bersumber pada hasil observasi kualitatif.

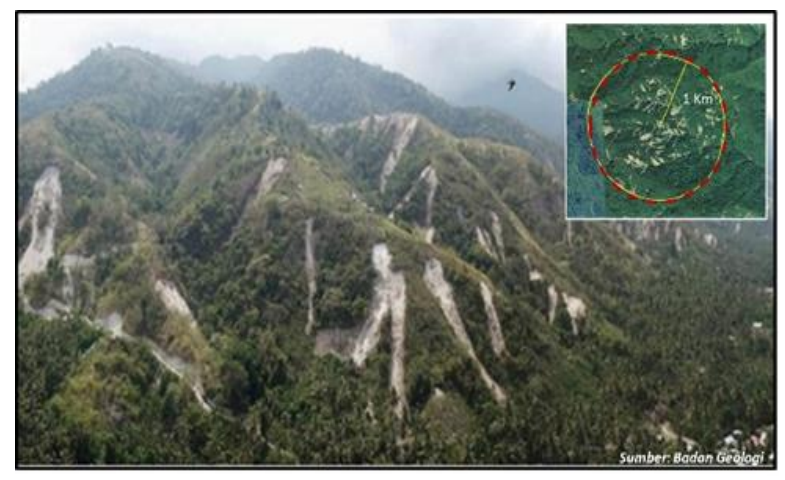

Gambar 2 Fenomena longsor di daerah Kabupaten Sigi, radius $1 \mathrm{Km}$ dari koordinat $119,32^{\circ} \mathrm{BT}$ dan $1,18^{\circ} \mathrm{LS}$

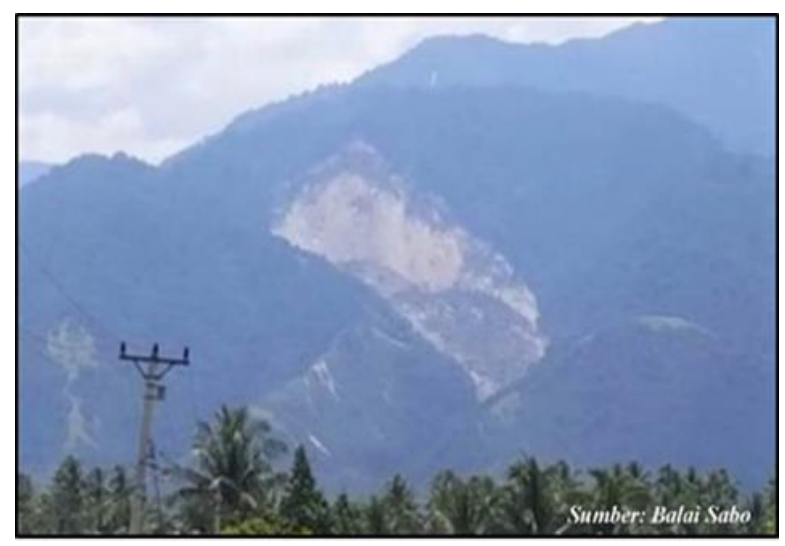

Gambar 3 Tanah longsor di lereng perbukitan Desa Poi, terletak pada koordinat $119,86^{\circ} \mathrm{BT}$ dan $-1.15^{\circ} \mathrm{LS}$ 


\section{HASIL DAN PEMBAHASAN}

Desa Poi merupakan salah satu dari 12 desa yang masuk wilayah Kecamatan Dolo Selatan, Kabupaten Sigi, Sulawesi Tengah. Luas wilayah Kecamatan Dolo Selatan adalah 584,71 km² dengan kondisi topografi terdiri dari tanah datar, perbukitan dan pegunungan yang berada pada ketinggian antara 50 - 122 meter dari permukaan laut.

Hasil survei lapangan di daerah pengkajian menunjukkan lokasi tanah longsor terletak pada koordinat 119,86517 BT dan -1,15379 LS. Luas tanah yang longsor adalah $599,721 \mathrm{~m}^{2}$, dengan perincian lebar $377 \mathrm{~m}$, panjang $1590,77 \mathrm{~m}$, kedalaman di daerah mahkota longsor $15 \mathrm{~m}$, dan kedalaman rata-rata $8 \mathrm{~m}$. Estimasi volume tanah longsor yang berada di kemiringan antara $40^{\circ}$ hingga $50^{\circ}$ di lereng perbukitan tersebut sekitar 4,8 juta $\mathrm{m}^{3}$.

Fenomena kawasan di daerah longsor, di bagian hulu terdapat banyak batang pohon tumbang sedang di bagian hilir terbentuk bendung alam. Material longsoran terdiri dari material lepas yang belum terkonsolidasi, memiliki tingkat kejenuhan air yang tinggi di musim hujan. (Pusat Litbang SDA, 2018).

Bendung alam yang terbentuk di lokasi tanah longsor di desa Poi diperkirakan akan mengakumulasi air hingga memiliki kekuatan yang mampu meruntuhkan tubuh bendung. Runtuhnya tubuh bendung yang terangkut aliran Sungai Poi mengakibatkan terjadinya aliran debris yang akan menyapu kawasan permukiman Desa Poi dan mengalir deras ke anak Sungai Palu.

Hasil identifikasi material longsor di Desa Poi berupa batuan dasar berumur tua yang mudah lapuk dan batuan metamorf yang terdiri dari batu sabak, kuarsit, batupasir kuarsa dengan sisipan batu lempung gampingan (berumur tua, terbentuk pada zaman kapur seratus juta tahun yang lalu), seperti dalam Tabel 1 berikut:

Tabel 1 Rincian batuan dasar material longsor

\begin{tabular}{ll}
\hline \multicolumn{3}{c}{ Batuan dasar material longsor di Desa Poi } \\
\hline Jenis & kerikil, gravel hingga boulder \\
Bentuk & granular yang mudah lepas \\
\hline *) Hasil identifikasi lapangan
\end{tabular}

Daerah pengkajian yang berada di lereng bukit Desa Poi merupakan daerah yang dekat dengan Garis Khatulistiwa, beriklim tropis dengan curah hujan cukup signifikan, rata-rata $>1.000 \mathrm{~mm}$ setahun. Bahkan di daerah tersebut pada bulan terkering masih sering terjadi hujan.

Air hujan yang jatuh ke permukaan tanah longsor, meresap ke dalam tanah akan meningkatkan kejenuhan tanah menyebabkan ikatan antar tanah menjadi renggang sehingga massa tanah mudah terangkut oleh aliran air. (Wiyanti, dkk. 2019). Kondisi material tanah longsor di tubuh bendung yang terangkut aliran air dalam skala besar berpotensi memicu terjadinya aliran debris yang diperkirakan melimpas ke daerah permukiman yang berada di hilirnya.

Kondisi hilir area longsor di lereng Desa Poi seperti tersaji pada Gambar 4 dengan kondisi dan karakteristik sebagai berikut :

1) aliran Sungai Poi yang merupakan sungai musiman (intermittent) yang mengalir ke arah timur menuju anak Sungai Palu,

2) Terdapat beberapa sumber mata air di Desa Poi, namun beberapa tertutup oleh material longsor.

3) Terdapat retakan-retakan dan nendatan pada permukaan tanah pada jaur menuju lokasi potensi aliran debris.

4) Di sebelah barat permukiman Desa Poi terdapat juga retakan dengan lebar antara 5 cm sampai mencapai $30 \mathrm{~cm}$ dan ketinggian nendatan mencapai $1 \mathrm{~m}$.

5) Luas subDAS anak Sungai Palu adalah $2,32 \mathrm{~km}^{2}$ dan panjang 2,96 km,

6) Terdapat batuan besar bekas aliran debris terakhir pada tahun 2007,

7) Terdapat bronjong pengarah yang saat ini kondisinya $80 \%$ telah tertimbun sedimen,

8) Lebar sungai rata rata 1 meter,

9) Ada 3 titik longsoran kecil mengarah ke sungai,

10) Dipuncak tebing banyak di jumpai rekahan searah sungai, berpotensi longsor saat terjadi hujan dan gempa berikutnya.

11) Tata guna lahan pada lokasi gerakan tanah secara umum didominasi oleh hutan dan kebun.

12) Lokasi permukiman berada pada lembah yang terletak di bagian hilir lereng yang longsor.

\section{Aplikasi pemodelan numerik Simulasi Lahar}

Awalnya Simulasi Lahar dibuat Dr. Miyamoto, Jepang tahun 1997. Aplikasi tersebut sudah digunakan di Jepang dan beberapa negara untuk analisis bahaya aliran lahar/debris dan membantu upaya mitigasinya. Tahun 2011, pemodelan numerik tersebut dikembangkan oleh Peneliti Balai Sabo, Pusat Litbang Sumber Daya Air, Badan Litbang Kementerian PU dengan sebutan aplikasi SIMLAR. Dalam mengembangkan aplikasi tersebut 
peneliti Balai Litbang Sabo bekerja sama dengan peneliti Universitas Gadjah Mada (UGM) dan Universitas Muhammadiyah Yogyakarta (UMY). Pengembangan tersebut meliputi penambahan sistem antarmuka (Graphical User Interface) , fungsi analisis hidrologi sintetis Nakayasu dan menu SIG. Sehingga dengan adanya sistem antarmuka tersebut memungkinkan operator mengoperasikan aplikasi SIMLAR dalam tampilan grafis secara mudah. (Balai Litbang Sabo, 2016).

Pengembangan aplikasi SIMLAR hingga saat ini telah mencapai SIMLAR 2.1. Hasil akhir dari skenario aplikasi tersebut diantaranya simulasi aliran banjir lahar/debris berbasis SIG. Simulasi tersebut berupa prediksi peta sebaran, tinggi aliran debris, tinggi erosi dan endapan, kecepatan aliran debris, volume aliran debris dan perubahan dasar saluran sungai yang akan terjadi. Pemodelan dilakukan dengan memasukkan parameter yang aktual terjadi di daerah pengkajian, seperti data hidrologi, topografi sungai, dan data hasil observasi kasar di lapangan seperti sedimentasi yang ada, potensi sedimen, dan lain-lain. Hasil pemodelan ini berupa zonasi daerah yang akan terdampak aliran debris dalam tampilan SIG.

Komponen pemodelan numerik SIMLAR terdiri dari:

1) Sub program penghitungan hidrograf banjir untuk menghasilkan hidrograf banjir akibat curah hujan efektif di daerah aliran sungai,
2) Sub program perhitungan hidrograf akibat keruntuhan bendung alam untuk menghasilkan hidrograf banjir akibat keruntuhan bendung alam,

3) Sub program simulasi 2D banjir untuk menghasilkan animasi banjir lahar/debris dan prakiraan daerah yang terancam/terdampak.

Data yang diperlukan untuk simulasi 2D diantaranya peta Digital Elevation Model (DEM), data sedimentasi (data distribusi gradasi sedimen), nilai kekasaran saluran manning, parameter rumusan angkutan sedimen, dan profil sungai. SIMLAR:

Persamaan dasar yang digunakan aplikasi

1) Rumus Angkutan Sedimen

2) Rumus empiris Keruntuhan Bendung Alam,

3) Hidrograf Satuan Sintetis Nakayasu.

Metode yang digunakan dalam aplikasi SIMLAR:

1) Konversi data hujan menggunakan metode Alternating Block Method (ABM).

2) Hubungan hujan dan debit aliran sungai dilakukan melalui telaahan hidrograf satuan sintetis Nakayasu

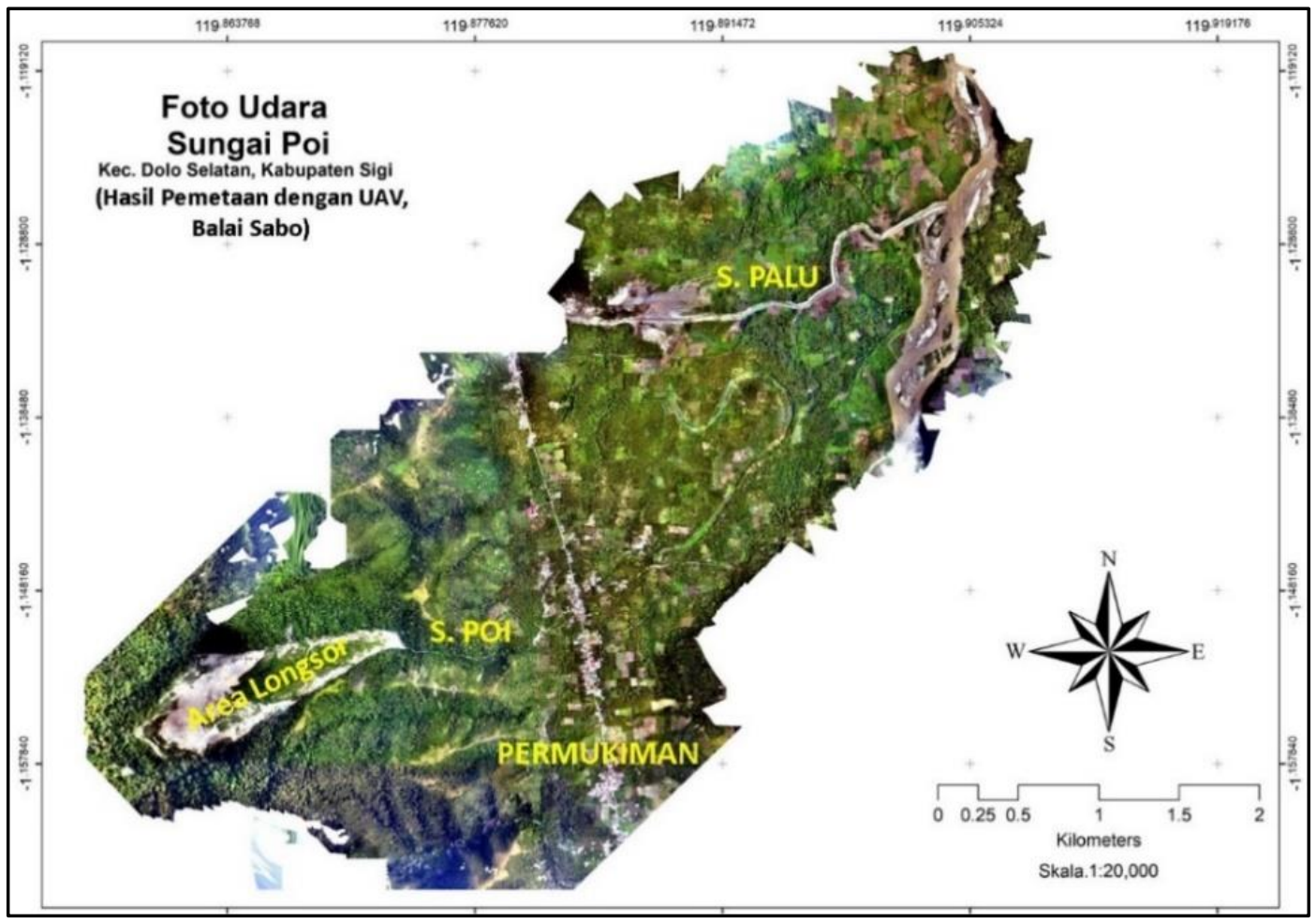

Gambar 4 Kondisi daerah longsor di Desa Poi, Kecamatan Dolo Selatandan sekitar 
3) Hidrograf banjir akibat runtuhnya bendung alam dilakukan melalui parameter empiris rekahan berupa durasi proses keruntuhan (waktu keruntuhan), lebar dasar bukaan bagian yang runtuh, dan kemiringan lereng bentuk bukaan.

Menu yang ada dalam pemodelan SIMLAR:

1) Hidrologi, digunakan untuk mengatur analisa konversi distribusi curah hujan dan hidrograf sintetik Nakayasu,

2) Topografi, untuk mengatur masukan data topografi peta DEM format.asc, batas daerah simulasi x: 400 dan Y: 2000

3) Koefisien parameter sedimentasi, untuk mengatur masukan data berat jenis sedimen dan potensi sumber sedimen,

4) Koefisien parameter sedimentasi dan morfologi sungai untuk mengatur masukan data parameter sedimen

5) Morfologi, hidrologi dan Iterasi perhitungan model untuk mengatur masukan data parameter sedimen,

6) Pilihan Output hasil simulasi untuk mengatur hasil model yang diinginkan.

\section{Prakiraan Banjir Debris dengan SIMLAR}

Prakirakan arah sebaran, rambatan dan kecepatan aliran banjir debris yang terjadi di lereng Desa Poi menggunakan aplikasi pemodelan numerik SIMLAR 2.1. Prakiraan debit banjir debris diperoleh berdasarkan debit banjir yang diperoleh dari analisa hidrologi curah hujan dan morfologi sungai serta data potensi endapan sedimen, potensi angkutan sedimen yang ada serta berdasarkan morofologi sungai dan kondisi topografi yang dienterpertasikan menggunakan data DEM.

Dari hasil pemodelan diperoleh kecepatan aliran debris sekitar $6,5 \mathrm{~m} /$ detik, menimbun 3 (tiga) desa di wilayah Kecamatan Dolo Selatan dalam waktu 4 menit, Desa Sambo, Balongga, dan Poi.

Tabel 2 Lokasi dan jumlah penduduk yang diperkirakan terdampak aliran debris

\begin{tabular}{lrrrc}
\hline \multicolumn{1}{c}{ Desa } & \multicolumn{1}{c}{ Luas } \\
(km2) & $\begin{array}{c}\text { Elevasi } \\
\text { (LMSL) }\end{array}$ & \multicolumn{2}{c}{$\begin{array}{c}\text { Penduduk } \\
\text { Jumlah } \\
\text { (jiwa) }\end{array}$} & $\begin{array}{l}\text { Kerapatan } \\
\text { (jiwa/km }{ }^{2} \text { ) }\end{array}$ \\
\hline Sambo & 6,79 & 80 & 1.080 & 159 \\
Balongga & 19,29 & 94 & 848 & 44 \\
Poi & 9,64 & 100 & 810 & 84 \\
\hline
\end{tabular}

*). Kecamatan Dolo Selatan dalam angka, 2019

Tabel 2, menujukkan hasil simulasi yang menunjukkan 3 (tiga) desa dari Kecamatan Dolo
Selatan yang terdampak aliran debris akibat tanah longsor di lereng Desa Poi.

Data lapangan yang diinputkan dalam pemodelan numerik SIMLAR tersebut berupa:

1) Hidrograf banjir dengan data hujan 300 $\mathrm{mm}$ /hari dengan kala ulang 50 tahun,

2) Data topografi berupa peta DEM keluaran Badan Informasi Geospasial, 2018 dengan resolusi $8,5 \mathrm{~m}$,

3) Potensi sedimen sebesar $4.174,107 \mathrm{~m}^{3}$.

Kecepatan aliran debris akibat intensitas hujan $300 \mathrm{~mm} /$ hari dengan kala ulang 50 tahun sekitar 6,5 m/detik. Perkiraan jangkauan aliran debris mencapai daerah permukiman di Desa Sambo, Balango dan Poi.

Hasil analisis arah, tinggi dan jarak aliran yang tersaji pada Tabel 2, menunjukan dalam sekali hujan dengan intensitas $300 \mathrm{~mm} /$ hari pada kala ulang 50 tahun mengakibatkan aliran debris sejauh $350 \mathrm{~m}$, mengarah ke permukiman setinggi 2,00 $5,20 \mathrm{~m}$.

Tabel 3 Kondisi aliran debris hasil Simulasi SIMLAR

\begin{tabular}{c|c|c}
\hline Hidrograf banjir & Arah dan Tinggi Aliran & $\begin{array}{c}\text { Jangkauan } \\
\text { Aliran }\end{array}$ \\
\hline $\begin{array}{c}\text { Data hujan } 300 \\
\text { mm/hari, kala } \\
\text { ulang 50 th }\end{array}$ & $\begin{array}{c}\text { Ke daerah pemukiman } \\
\text { tinggi 2,00-5,20 m }\end{array}$ & $350 \mathrm{~m}$ \\
*). Analisis dari hasil Aplikasi SIMLAR &
\end{tabular}

Tabel 3. Menunjukkan hasil analisis angkutan sedimen dengan data hujan $300 \mathrm{~mm} /$ hari kala ulang 50 tahun.

Hasil analisis angkutan sedimen yang tersaji pada Tabel 4, menunjukan dalam sekali hujan dengan intensitas $300 \mathrm{~mm} /$ hari, kala ulang 50 tahun mengaki-batkan terangkutnya sedimen sekitar 312 ribu $\mathrm{m}^{3}$. Secara keseluruhan daerah berisiko terpapar angkutan sedimen seluas $2.320 \mathrm{~km}^{2}$.

Gambar 5 menunjukkan peta terdampak debris dari hasil simulasi prakiraan banjir debris di daerah tanah longsor Desa Poi dengan aplikasi SIMLAR. Gambar 6 merupakan peta terdampak debris hasil Simulasi SIMLAR di Desa Poi, dalam tampilan Peta RBI skala 1: 50.000, Digital Elevation Mode dari Badan Informasi Geospasial 2018.

Prakiraan ini dapat terjadi mengingat kondisi material sedimen longsor di daerah tersebut belum termampatkan dan masih berbentuk granuler sehingga mudah hanyut oleh aliran permukaan.

Tabel 4 Hasil analisis angkutan sedimen dengan data hujan $300 \mathrm{~mm} /$ hari kala ulang 50 tahun 


\begin{tabular}{|c|c|c|c|c|c|}
\hline $\begin{array}{c}\text { Tan } \Theta \\
\text { (konsen- } \\
\text { trasi } \\
\text { sedimen) }\end{array}$ & $\begin{array}{c}\mathrm{Cd} \\
\text { (Koefisien } \\
\text { kekasaran } \\
\text { Manning, } \\
\mathrm{g} / \mathrm{m}^{\mathrm{m}} \text { ) }\end{array}$ & $\begin{array}{c}\text { luas } \\
\text { daerah } \\
\text { endapan } \\
\left(\mathrm{km}^{2}\right)\end{array}$ & & $\mathrm{Fr}$ & $\begin{array}{c}\text { Volume } \\
\text { sedimen } \\
\text { Vs }\left(\mathrm{m}^{3}\right)\end{array}$ \\
\hline $0,325^{0}$ & 0,55 & 2.320 & 0,21 & 0,21 & $312.358,7$ \\
\hline
\end{tabular}

*). Analisis dari hasil Aplikasi SIMLAR

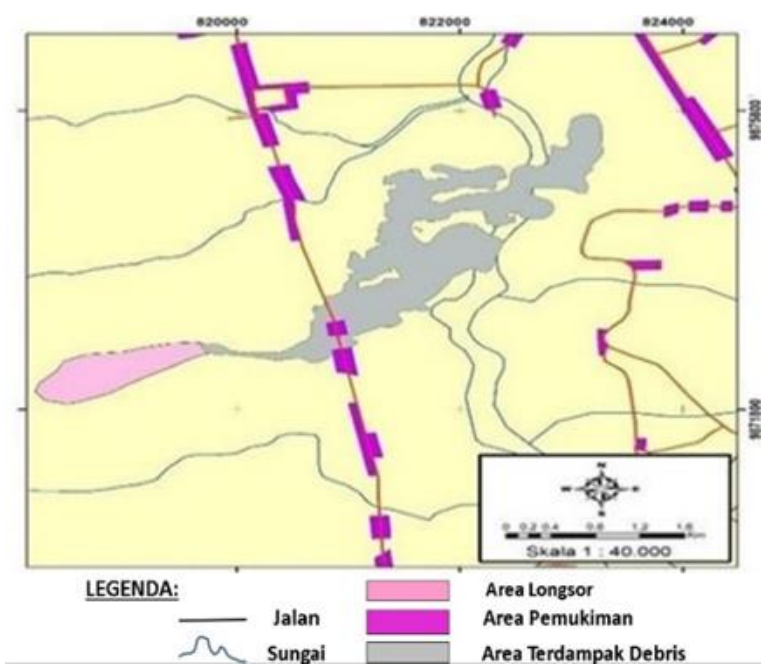

Gambar 5 Peta terdampak debris hasil Simulasi SIMLAR

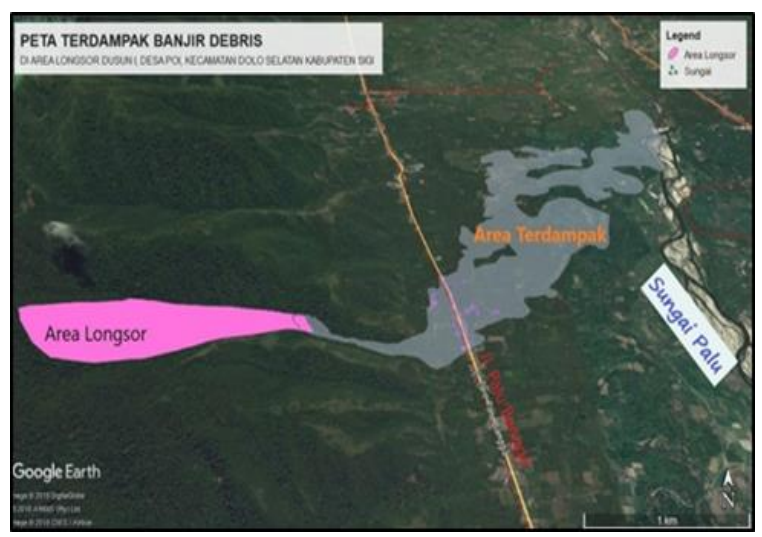

Gambar 6 Peta terdampak debris dari hasil simulasi prakiraan banjir debris di daerah tanah longsor Desa Poi

\section{Pemetaan Aliran Debris Pasca Tanah Longsor}

Pada tanggal 8 Desember 2019 telah terjadi aliran debrisawal pasca longsor di daerah pengkajian yang dipicu curah hujan dengan intensitas 46,8 mm. Gambar 7 menunjukkan peta limpasan aliran debris awal pasca longsor yang terjadi dilereng Desa Poiyang pemetaannya disusun berdasarkan data hasil identifikasi yang diambil dari pemantauan pesawat tanpa awak (drone) atau Unmanned Aerial Vehicle (UAV).

Hasil analisis peta menunjukkan luas limpasan aliran debris yang dipicu oleh curah hujan $46,8 \mathrm{~mm}$ sekitar 11 Ha. Dari peta luas limpasan aliran debris tersebut terlihat bahwa prediksi peta sebaran aliran debrisnya mendekati sama dengan hasil pemodelan SIMLAR, hanya karena jumlah curah hujan pemicunya kecil maka aliran debris pada awal pasca longsor tersebut mempunyai tinggi aliran dan endapannya lebih kecil. Bahkan dari hasil identifikasi lapangan terlihat volume aliran debris dan perubahan dasar saluran sungai belum maksimal.

\section{Penanggulangan Bencana Debris}

\section{1) Mitigasi Bencana}

Menurut UU No 24 Tahun 2007 dan Peraturan Pemerintah Nomor 21 Tahun 2008 tentang penanggulangan bencana dan penyelenggaraannya, mitigasi didefinisikan sebagai upaya yang ditujukan untuk mengurangi dampak dari bencana. Lingkup kegiatan mitigasi bencana bertujuan untuk mengurangi dan/atau meniadakan korban jiwa dan kerugian harta benda. Untuk itu, dalam menangani aliran debris dan runtuhnya bendung alam di daerah pengkajian perlu melakukan mitigasi bencana secara struktural dan non-struktural serta upaya pengendalian banjir debris dengan teknologi sabo.

Mitigasi bencana struktural adalah upaya pengurangan dampak bencana melalui konstruksi atau perubahan lingkungan fisik dengan mengaplikasikan solusi bersifat teknis. Mitigasi bencana non-struktural merupakan upaya pengurangan risiko dengan cara memodifikasi perilaku manusia atau proses alam tanpa memerlukan struktur teknis. Misalnya: penyusunan dan penerbitan suatu peraturan, pembuatan tata ruang kota sebagai upaya antisipasi bencana, capacity building masyarakat, penguatan kapasitas masyarakat peduli bencana.

Penguatan kapasitas masyarakat dalam menghadapi bencana dapat menumbuh kembangkan kearifan lokal warisan nenek moyang berupa perpaduan antara agama dan budaya untuk mitigasi bencana. (Ruslanjari. D. dkk. 2018).

Mitigasi non struktural merupakan upaya pengurangan risiko bencana berkelanjutan karena memberikan keamanan dalam jangka panjang. (Dewi I.K. dan Istiadi Y. 2016).

2) Pengendalian debris dengan teknologi sabo

Teknologi Sabo adalah suatu teknik yang digunakan untuk mengantisipasi aliran debris/lahar dan pengendalian sedimen dalam suatu bentang alam, khususnya pada sungai di daerah vulkanik maupun non-vulkanik. Teknologi ini sangat bermanfaat untuk penanggulangan bencana yang sifatnya jangka panjang serta bersifat periodik. 


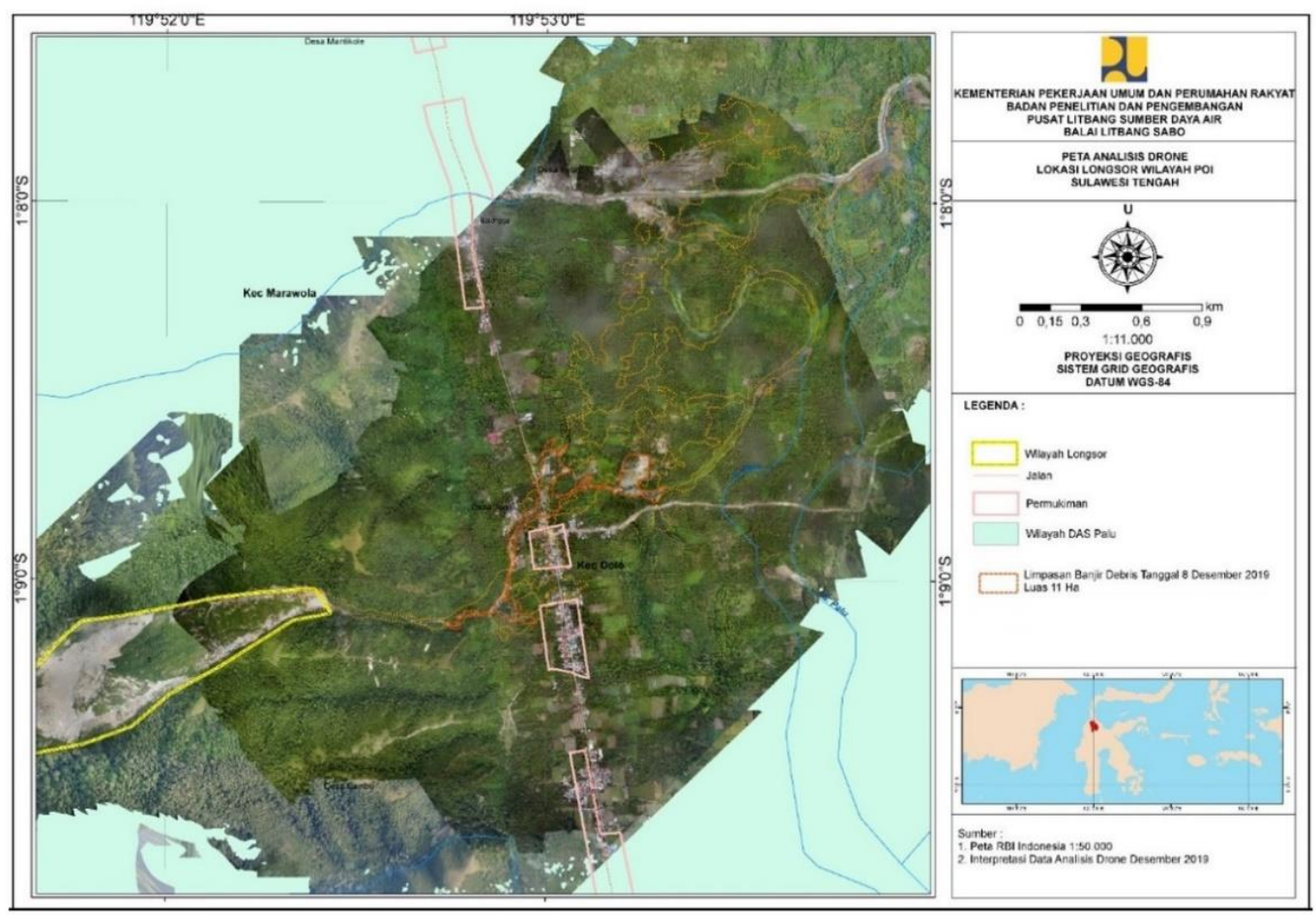

Gambar 7 Hasil pemetaan aliran debris pada tanggal 8 Desember 2019.

(1) Teknologi sabo secara fisik.

Berupa pengendalian aliran debris/lahar dengan membangun berbagai infrastruktur fisik yang menggunakan pendekatan teknologi Sabo berupa bangunan sabo beserta fasilitasnya yang dibangun melintang alur sungai. Pemilihan bangunan sabo di daerah pengkajian ini bertujuan untuk mengendalikan sedimen dengan cara menahan, menampung dan mengalirkan material sedimen yang terbawa oleh aliran dan meloloskan air ke hilir. Diharapkan melalui bangunan sabo tersebut aliran debris dalam skala besar yang mengalir melalui alur sungai dapat diperlambat, agar sedimen yang terlarut dalam aliran tersebut mengendap di dasar sungai. Pengendapan sedimen di dasar sungai dapat mengurangi daya rusak aliran debris sehingga dampak yang terjadi di daerah hilir berkurang.

\section{(2) Teknologi sabo secara non-fisik.}

Merupakan pengendalian aliran debris yang difokuskan pada usaha-usaha di luar upaya fisik ,seperti sistem prakiraan dan peringatan dini, membuat peta rawan bencana, sosialisasi ke masyarakat untuk meningkatkan kewaspadaan, dan relokasi. Pengendali aliran debris dengan teknologi sabo secara non-fisik berupa pemasangan peralatan sistem prakiraan dan peringatan dini aliran debris.

Pembangunan sistem tersebut merupakan upaya pendukung dari pengendalian bencana debris secara fisik agar ketika upaya tersebut mengalami kegagalan tetap masih dapat mengurangi korban jiwa dan kerugian harta benda.

Volume tanah longsor di kawasan lereng Desa Poi yang masuk ke alur sungai dalam jumlah besar telah membentuk bendung alam. Aliran air hujan yang sering terjadi di hulu bendung alam semakin lama akan menambah volume material bendung tersebut. Bertambahnya volume bendung mengakibatkan jumlah aliran air yang mengalir di sungai tersebut semakin tertahan. Ketika intensitas hujan yang terjadi di daerah hulu atau disekitar daerah longsor semakin tinggi mengakibatkan aliran airnya terakumulasi, sehingga dalam waktu tertentu akan meruntuhkan bendung alam yang ada.

Akibat runtuhnya bendung alam tersebut, memicu aliran debris yang mengangkut sejumlah material yang tertampung di dasar bendung. Aliran debris tersebut akan mengalir ke arah Timur menuju ke permukiman Desa Poi dan anak Sungai Palu. Ketersediaan material sedimen hasil runtuhnya bendung alam lereng Desa Poi dapat memicu terbentuknya bendungan alam berikutnya di anak Sungai Palu. (Azmeri, dkk. 2017).

Aliran debris yang meruntuhkan bendung alam di Sungai Poi berpotensi pula meruntuhkan bendung alam yang terbentuk di anak Sungai Palu. Runtuhnya ke dua bendung alam tersebut merupakan efek domino dari aliran debris yang berawal dari gempa bumi Palu yang mengakibatkan tanah longsor di lereng Desa Poi. 
Luncuran aliran debris yang mengalir di daerah pengkajian merupakan luncuran dangkal. Hal ini ditengarai oleh proses terbentuknya aliran debris yang berawal dari lapisan tanah di dekat permukaan yang mengalami kejenuhan air hujan dan yang tergerus aliran. Aliran tersebut selain mengangkut material yang tertampung di dasar alur bendung juga mengangkut material dari lapisan tanah permukaan alur dan tebing sungai yang dilaluinya.

Untuk mengendalikan aliran debris yang mengangkut material yang tertampung di dasar alur bendung, dari lapisan tanah permukaan alur serta tebing sungai digunakan teknologi sabo secara fisik dan non-fisik. (Sukatja. C.B, 2016).

Pengendalian debris dengan teknologi sabo secara fisik yang paling efektif menggunakan bangunan sabo (Kim, N.2015), diantaranya:

a) beberapa sabodam yang dibangun secara seri untuk meredam volume material aliran debris (detention storage) agar debit maksimum yang dilepas ke hilir sama dengan debit dominan alur hilir (Alvianto, A. dkk. 2019),

b) satu atau beberapa Ground sill yang dibangun secara seri supaya pada alur transportasi terjadi aliran berjenjang untuk mengurangi kemiringan dasar sungai dan kecepatan aliran debrisnya,

c) membuat beberapa kolam penampungan (embung) untuk menambah volume penangkapan sedimen di alur sungai yang berada di hilir bendung alam, khususnya pada daerah yang memungkinkan, dengan memanfaatkan galur-galur erosi (gullies).

Ketentuan tataletak dan lokasi bangunan sabo yang digunakan dalam pengendalian debris di lokasi pengkajian harus disesuaikan dengan:

1) Pemilihan lokasinya harus menghasilkan bangunan yang sesuai standar namun paling ekonomis, dimana biaya pembangunan bila dikaitkan dengan daya tampungnya mempunyai nilai yang paling kecil,

2) sumbu sabodam harus tegak lurus dengan arah aliran di bagian hilirnya,

3) lokasi sabodam diusahakan agar di bagian hulu bangunan sabo dapat menampung sedimen yang maksimum,

4) untuk mengantisipasi terjadinya limpasan dan gerusan pada tebing luar tikungan yang berada di hulu maupun di hilir bangunan maka sebelum membangun sabodam di tikungan sungai harus disertai dengan tinjauan hidraulik.
Pertimbangan jumlah bangunan sabo sebagai peredam aliran debris disesuaikan dengan besar volume atau frekuensi banjir yang harus diredam dan ditampung. Hal ini tergantung kepada besar volume tampungan yang tersedia. Sedang perencanaan besar volume tampungan yang tersedia pada bangunan sabo, disesuaikan dengan kelandaian dan panjang dari alur sungai, ketinggian tebing di sepanjang alur sungai.

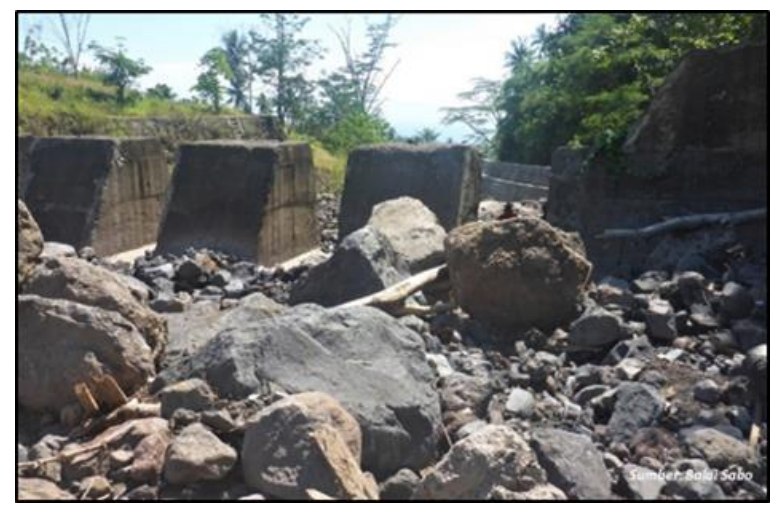

Gambar 8 Sabodam tipe celah mampu menahan material batuan dan batang pohon besar

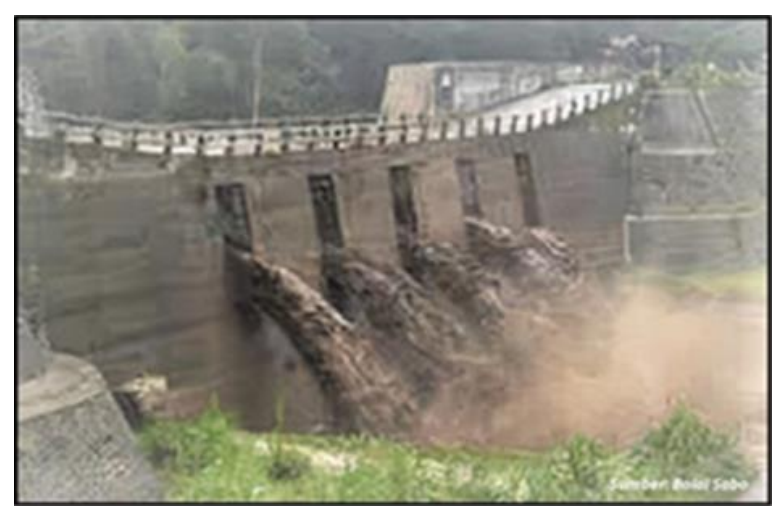

Gambar 9 Sabodam tipe gorong-gorong digunakan sebagai jembatan dan penahan material batuan besar

Aliran debris yang terjadi di Sungai Poi dan anak Sungai Palu merupakan bencana hidrometeorologi yang dipicu parameterparameter meteorologi. Untuk mendukung kinerja sistem prakiraan dan peringatan dini aliran debris memerlukan sejumlah peralatan pendukung, diantaranya pemantau hidrologi, pergerakkan tanah berbasis jejaring sensor nirkabel, serta sistem alarm.

Sehubungan aliran debris yang terjadi di daerah pengkajian tersebut mengangkut material sedimen berupa kerikil, gravel, boulder maka desain pembangunan sabodam dengan:

1) tipe celah (slit sabo) tunggal atau celah ganda, merupakan upaya yang efektif dalam mitigasi 
jangka pendek terhadap aliran debris atau banjir bandang. (M. Silva et al., 2016),

2) tipe gorong-gorong (culvert sabo), desain lubang gorong-gorongnya harus disesuaikan dengan diameter maksimum material yang akan melewatinya,

3) bahan yang digunakan untuk membangun sabodam gorong-gorong harus memperhitungkan dengan kecepatan aliran pada debit maksimum.

Gambar 8 dan Gambar 9 menunjukkan contoh bangunan sabodam tipe celah dan tipe goronggorong yang mampu menahan material batuan besar dan batang pohon besar.

Untuk mengantisipasi terjadinya kegagalan sabodam akibat adanya unsur alam, teknis, penambangan sedimen yang tak terkendali maka pengendalian aliran debris di Desa Poi perlu didukung pengendalian debris secara non fisik. Disamping itu dengan pengendalian debris gabungan antara cara fisik dan non-fisik juga akan memberi rasa aman bagi masyarakat yang tinggal di sekitar bangunan sabo. Sungai Poi dilakukan dengan membangun peralatan sistem prakiraan dan peringatan dini aliran debris.

Untuk itu dalam mengendalikan aliran debris secara non-fisik akibat runtuhnya bendung alam di-Sungai Poi dilakukan dengan membangun peralatan sistem prakiraan dan peringatan dini aliran debris.

Beberapa peralatan pendukung sistem prakiraan dan peringatan dini aliran debris, adalah:

1) Penakar curah hujan (Automatic Rain Recorder),

Peralatan hidrologi ini dipasang di daerah sekitar tanah longsor untuk mengetahui jumlah hujan yang terjadi di daerah pengkajian. Data intensitas hujan yang diamati dapat dipergunakan untuk memprakirakan pergerakan tanah dari bendung alam yang dapat memicu terjadinya aliran debris. Dengan diketahuinya data jumlah hujan yang dapat memicu pergerakan tanah sangat berguna dalam meningkatkan kewaspadaan masyarakat yang tinggal di daerah berpotensi terdampak aliran debris.

\section{2) GPS (Global Positioning System),}

Alat ini merupakan peralatan sistem satelit navigasi yang mampu memberikan informasi tentang posisi, kecepatan dan waktu secara kontinyu sehingga cocok digunakan untuk mendeteksi pergerakan tanah secara dini.

Dengan sistem GPS ini data pergerakan tanah dari lereng di daerah pengkajian dikirimkan ke satelit kemudian dikirimkan kembali ke pos/stasiun pemantauan dan untuk selanjutnya diteruskan ke stasiun induk penerima data. Data yang sudah diterima di stasiun induk dianalisis untuk menentukan level atau status dari bendung alam yang mengalami pergerakan tanah. Apakah pergerakan tanah tersebut sudah mencapai volume yang bila terangkut air hujan dapat memicu terjadinya aliran debris.

\section{3) Inclinometer,}

Peralatan ini digunakan untuk memantau pergerakan yang terjadi di bawah permukaan tanah, seperti pergerakan tanah di daerah longsor, di area bendung alam, maupun di tanggul dan sebagainya. Data hasil pemantauan peralatan ini digunakan untuk lebih memastikan bahwa di daerah pengkajian sudah mulai mengalami pergerakan tanah yang bila terangkut air hujan dapat memicu terjadinya aliran debris.

4) Sirene dan Lampu Alarm,

Peralatan Sirene dan Lampu alarm merupakan peralatan untuk memberitahukan kondisi pergerakan tanah di beberapa tempat dari tubuh bendung yangmulai mengalami pergerakan tanah. Adanya data mulai terjadinya pergerakan tanah dibeberapa tempat di tubuh bendung sangat membantu masyarakat untuk meningkatkan kewaspadaan agar mempunyai cukup waktu untuk mengungsi.

Tersedianya tenggang waktu peringatan yang cukup dapat mendukung terlaksananya kegiatan dalam perencanaan pra bencana secara baik.

\section{Sistem prakiraan dan peringatan dini debris}

Sistem prakiraan dan peringatan dini aliran debris yang direncanakan di daerah pengkajian ada 2 macam, yaitu:

1) Sistem peringatan dini aliran debris (alert
system)

Sistem ini adalah suatu sistem terpadu yang dipasang di daerah endapan material longsor untuk memberikan informasi telahterjadi pergerakan tanah yang diperkirakan dapat memicu terjadinya aliran debris. Peralatan tersebut merupakan sebuah sistem yang mengintegrasikan data/informasi, pengolahan, dan analisis cepat yang akan menghasilkan informasi terjadinya aliran debris melalui bunyi sirine dan menyalanya lampu alert.

Gambar 10 merupakan peralatan sistem peringatan dini debris (alert system). Contoh tata letak lokasi pemasangan sistem peringatan dini debris di daerah pengkajian dapat diihat pada Gambar 11. 
2) Sistem prakiraan dan peringatan dini aliran debris telemetri.

Sistem ini merupakan serangkaian sistem pendeteksi data beberapa gejala alam yang dapat menimbulkan tanah longsor serta aliran debris yang pembacaan hasil pendeteksiannya dilakukan dari jarak relative jauh.

Sistem tersebut terdiri dari stasiun pemantau gerakan tanah sistem telemetri di lapangan dan stasiun induk penerima data.

Data yang terdeteksi oleh beberapa sensor di daerah pengkajian terlebih dahulu dikumpulkan di pos/stasiun pemantauan kemudian dikirim ke stasiun induk penerima data melalui jaringan gelombang radio. Selanjutnya data dari stasiun induk penerimadikirimkan ke BPBD setempat agar dapat disebarluas- kan ke instansi terkait, relawan peduli bencana dan masyarakat yang berpotensi terdampak aliran debris.

Desain stasiun pemantau gerakan tanah sistem telemetri yang dipasang di lapangan seperti pada Gambar 12. Contoh tata letak lokasi pemasangannya seperti dalam Gambar 13.

Desain stasiun pemantau gerakan tanah sistem telemetri terdiri dari Tower, Catu daya arus searah, Radio pemancar dan Modem, Antena Radio dan GPS, Data Logger, Penakar Hujan sebanyak 2 set, GPS sebanyak 6 set Sensor Inclinometer dan 1 set Lampu Alert dan Sirine.

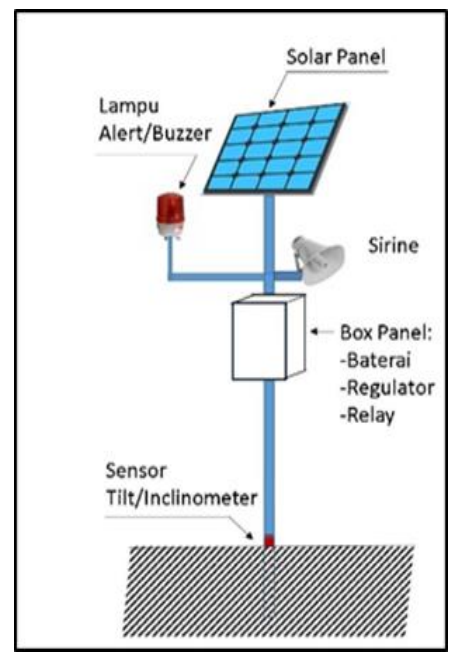

Gambar 10 Peralatan sistem peringatan dini debris (alert system)

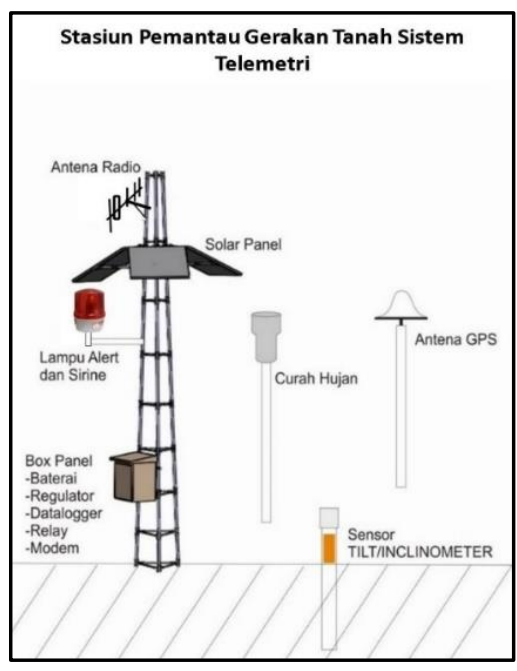

Gambar 12 Stasiun pemantau gerakan tanah sistem telemetri di lapangan

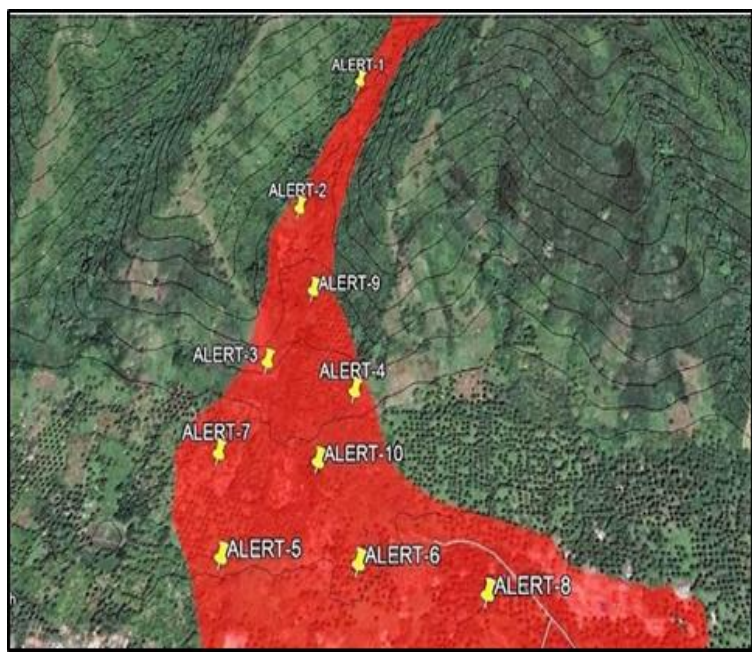

Gambar 11 Contoh tata letak lokasi pemasangan sistem peringatan dini debris

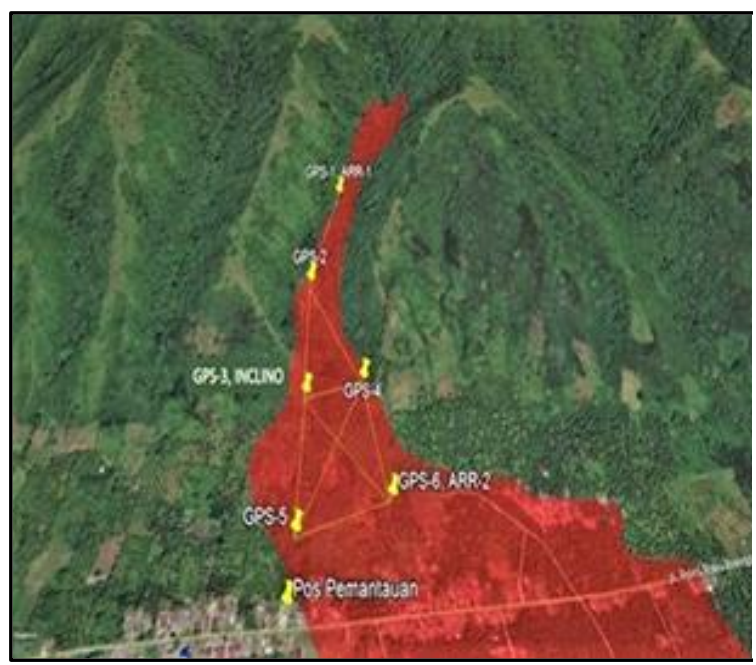

Gambar 13 Contoh tata letak Stasiun pemantau gerakan tanah sistem telemetri di lapangan 


\section{KESIMPULAN}

Lokasi bendung alam yang berada di dekat garis khatulistiwa, beriklim tropis dengan curah hujan tinggi, dalam dekade ini sering mengalami anomali iklim La-Nina. Catatan historis menunjukkan bahwa LaNina dapat menyebabkan terjadinya peningkatan akumulasi jumlah curah hujan bulanan hingga $40 \%$ di atas normalnya. Dengan peningkatan akumulasi curah hujan di daerah pengkajian diperkirakan aliran air yang tertahan oleh bendung alam semakin terakumulasi, sehingga berpotensi meruntuhkan bendung alam dalam waktu yang tidak lama.

Sehubungan kondisi alam daerahnya dengan runtuhnya bendung alam di lereng Desa Poi perlu diwaspadai adanya "efek domino" dari runtuhnya bendung alam yang terbentuk di Sungai Palu agar korban jiwa dan harta benda dapat diminimalisir,

Kearifan lokal nenek moyang yang terdapat di daerah pengkajian merupakan modal sosial dalam mitigasi bencana non-struktural untuk meningkatkan rasa kebersamaan dalam menghadapi bencana. Dengan meningkatnya rasa kebersamaan dari masyarakat akan tercipta rasa saling menguatkan diantara warga terdampak bencana yang pada akhirnya terbentuk masyarakat tangguh menghadapi bencana yang mampu hidup berdampingan dengan bencana

Hasil aplikasi SIMLAR 2.1 yang berupa peta terdampak debris di daerah pengkajian, meliputi arah jangkauan dan tinggi serta luasan daerah yang terdampak bencana debris. Dengan diketahuinya daerah yang berisiko terpapar aliran debris dapat dimanfaatkan untuk meningkatkan kesiap siagaan masyarakat yang bermukim atau beraktivitas di hilir bendung alam sehingga dapat menurunkan risiko korban jiwa/harta benda,

Pemanfaatan Teknologi sabo secara fisik dan non-fisik merupakan rekomendasi yang tepat dalam penanganan dan pengendalian bencana debris akibat runtuhnya bendung alam lereng Desa Poi. Namun untuk menghindari terjadinya kegagalan dalam pengurangan risiko bencana debris sebaiknya penggunaan teknologi sabo secara fisik dan non-fisik dilaksanakan dalam satu kesatuan seperti yang direkomendasikan.

Pemilihan sabodam tipe celah tunggal atau ganda dan sabodam gorong-gorong dengan desain lubang yang disesuaikan dengan diameter maksimum material yang akan melewatinya dapat mengurangi risiko kerusakan infrastruktur di daerah pengkajian.

Upaya mitigasi dan penanggulangan bencana debris pasca gempa bumi Palu dengan membangun sabodam dan sistem prakiraan dan peringatan dini bencana debris memberikan rasa aman dan waktu yang cukup bagi masyarakat bila harus melakukan pengungsian. Disamping itu dengan upaya tersebut menunjukkan kepedulian serta kehadiran negara dalam mendampingi warga negaranya yang berpotensi terdampak bencana.

\section{UCAPAN TERIMA KASIH}

Terima kasih kepada Ibu Dr. Yunnita Chandra Sari, SE; ST; M. T. Kepala Balai Teknik Sabo dan siapa saja yang telah mendukung tersusunnya jurnal ini.

\section{DAFTAR PUSTAKA}

Alfianto, A., Iswardoyo, J., \& Sukatja, C. B. (2019). Efektivitas dan Kelengkapan Bangunan Sabo di Sungai Togurara Daerah Gunungapi Gamalama. .Jurnal Teknik Hidraulik, 10(2),90 103.

Azmeri, Fatimah, E., Herawati, H., Sundary, D., Isa, A. H. (2017). Analisis Spasial Risiko Banjir Bandang Akibat Keruntuhan Bendungan Alami pada DAS Krueng Teungku, Kabupaten Aceh Besar, Provinsi Aceh. Jurnal Teknik Sipil ITB, 24(3). DOI: $10.5614 /$ jts.2017.24.3.6

Badan Informasi Geospasial (2018). Digital Elevation Model Nasional dengan resolusi 8,5 $\mathrm{m}$, tahun 2018. Diakses dari http://tides.big.go.id/DEMNAS/

Balai Litbang Sabo. (2016). Panduan Simulasi Banjir Lahar 2D SIMLAR 2.1 (2016). Laporan Akhir kegiatan Penelitian 2016 (Puslitbang SDA)

BMKG. (2018). Ulasan Guncangan Tanah Akibat Gempa Bumi Utara Donggala Sulteng, 28 September 2018, Bidang Seismologi Teknik BMKG. https://cdn.bmkg.go.id/Web/UlasanGempa-

DONGGALA 28092018 rev13102018.pdf (diunduh 24 September 2020).

BNPB. (2018) Kerugian dan Kerusakan Dampak Bencana di Sulawesi Tengah Mencapail 13,82 Trilyun Rupiah. Senin, 22 Oktober 2018 02:29 WIB. https://bnpb.go.id/berita/kerugian-dankerusakan-dampak-bencana-di-sulawesitengah-mencapai-1382-trilyun-rupiah. (diunduh 01 Februari 2021).

Dewi, I.K. \& Istiadi, Y. (2016). Mitigasi Bencana pada Masyarakat. Jurnal Manusia dan Lingkungan, 23(1), 129-135. https://doi.org/10.22146/jml.18782 
Kim, N. (2015). Numerical Study on Debris-Flow Behavior. A dissertation of Doctoral Degree in Civil and Earth Resources Engineering, Disaster Prevention Research Institute, River Disaster Prevention Systems Laboratory, Department of Civil and Earth Resources Engineering, Kyoto University, Japan.

Silva, M., Costa, S., Canelas, R.B., Pinheiro, A.N., \& Cardoso, A.H. (2016). Experimental and Numerical Study of Slit-Check Dams. International Journal for Sustainable Development and Planning. Vol. 11, No. 2 (2016) 107-118.

DOI:10.2495/SDP-V11-N2-107-118

Negara Republik Indonesia. Undang Undang tentang Penanggulangan Bencana No 24 Tahun 2007.

Peraturan Pemerintah tentang Penyelenggaraan Bencana Nomor 21 Tahun 2008.

Pusat Sudi Gempa Nasional dan Pusat Litbang Perumahan dan Pemukiman - Balitbang PUPR Geotechnical Report on 2018 Palu-Donggala Earthquake, ISBN: 978-602-5489-19-8, 2019,

Ruslanjari, D. \& Dewi, T. P. (2018). The Social Capital in Community Preparedness Towards the Landslide Disaster in Pagerharjo Kulonprogo. Jurnal Universitas Gadjah Mada. DOI 10.22146/kawistara. 28069. Vol. 8 No. 22 Desember 2018 https://doi.org/10.22146/kawistara.28069
Suardiari, G., Supardi, \& Mulyono, J. (2019). Kerusakan dan Perilaku Bendungan Hasil Inspeksi Luar Biasa Akibat Gempa Lombok. Jurnal Infrastruktur, 5(01). p-ISSN 2527-497X, e-ISSN 2580-4448.

Sukatja, C. B. (2016). Investigation on Disaster Risk of Sinabung Volcano. International Journal of Academic Research, Vol. 8 No. 4 July 2016, Part A Applied and Natural Sciences, ISSN:20754124, E-ISSN:2075-7107, July 2016: 18 - 26. DOI:10.7813/2075-4124.2016/8-4/A.3

Widjaja, B. \& Gautama, K.A. (2019). Prediksi Dampak Longsor Susulan di Desa Poi Palu dengan Model Bingham. Prosiding Seminar Nasional Teknik Sipil 2019. Fakultas Teknik Universitas Muhammadiyah Surakarta. ISSN: 2459727. Diakses dari https://www. researchgate.net / publication/ 334227246Prediksi Dampak Longsor Susula n di Desa Poi Palu dengan Model Bingham

Wiyanti, N. M. D. P \& Kusmawati, T. (2019). Pemetaan Potensi dan Kerawanan Longsor Lahan di Desa Belandingan, Desa Songan A dan Desa Songan B Kecamatan Kintamani, Kabupaten Bangli. Jurnal Agroekoteknologi Tropika ISSN: 23016515 Vol. 8, No. 2, April 2019 Diakses dari https://ojs.unud.ac.id/index.php/JAT231. (diunduh 8 September 2020) 
Jurnal Teknik Hidraulik Vol. 12 No.1, Juni 2021: 25 - 38 